\title{
Stenting and interventional radiology for obstructive jaundice in patients with unresectable biliary tract carcinomas
}

\author{
Toshio Tsuyuguchi ${ }^{1}$, Tadahiro Takada ${ }^{2}$, Masaru Miyazaki $^{3}$, Shuichi Miyakawa ${ }^{4}$, Kazuhiro Tsukada $^{5}$, \\ Masato Nagino ${ }^{6}$, Satoshi Kondo ${ }^{7}$, Junji Furuse ${ }^{8}$, Hiroya Saito ${ }^{9}$, Masafumi Suyama ${ }^{10}$, Fumio Kimura ${ }^{3}$, \\ Hideyuki Yoshitomi ${ }^{3}$, Satoshi Nozawa ${ }^{3}$, Masahiro Yoshida ${ }^{2}$, Keita Wada ${ }^{2}$, Hodaka Amano ${ }^{2}$, \\ and FuMihiko MiUrA ${ }^{2}$ \\ ${ }^{1}$ Department of Medicine and Clinical Oncology, Chiba University Graduate School of Medicine, 1-8-1 Inohana, Chuo-ku, Chiba 260-0856, \\ Japan \\ ${ }^{2}$ Department of Surgery, Teikyo University School of Medicine, Tokyo, Japan \\ ${ }^{3}$ Department of General Surgery, Chiba University Graduate School of Medicine, Chiba, Japan \\ ${ }^{4}$ Department of Gastroenterological Surgery, Fujita Health University, Toyoake, Japan \\ ${ }^{5}$ Department of Surgery and Science, Graduate School of Medicine and Pharmaceutical Science for Research, University of Toyama, Toyama, \\ Japan \\ ${ }^{6}$ Division of Surgical Oncology, Department of Surgery, Nagoya University Graduate School of Medicine, Nagoya, Japan \\ ${ }^{7}$ Department of Surgical Oncology, Hokkaido University Graduate School of Medicine, Sapporo, Japan \\ ${ }^{8}$ Hepatobiliary and Pancreatic Oncology Division, National Cancer Center Hospital East, Chiba, Japan \\ ${ }^{9}$ Department of Radiology, Asahikawa Kosei General Hospital, Asahikawa, Japan \\ ${ }^{10}$ Department of Gastroenterology, Juntendo University, Tokyo, Japan
}

\begin{abstract}
Together with biliary drainage, which is an appropriate procedure for unresectable biliary cancer, biliary stent placement is used to improve symptoms associated with jaundice. Owing to investigations comparing percutaneous transhepatic biliary drainage (PTBD), surgical drainage, and endoscopic drainage, many types of stents are now available that can be placed endoscopically. The stents used are classified roughly as plastic stents and metal stents. Compared with plastic stents, metal stents are of large diameter, and have long-term patency (although they are expensive). For this reason, the use of metal stents is preferred for patients who are expected to survive for more than 6 months, whereas for patients who are likely to survive for less than 6 months, the use of plastic stents is not considered to be improper. Obstruction in a metal stent is caused by a tumor that grows within the stent through the mesh interstices. To overcome such problems, a covered metal stent was developed, and these stents are now used in patients with malignant distal biliary obstruction. However, this type of stent has been reported to have several shortcomings, such as being associated with the development of acute cholecystitis and stent migration. In spite of these shortcomings, evidence is expected to demonstrate its superiority over other types of stent.
\end{abstract}

Key words Biliary stenting - Biliary tract cancer - Obstructive jaundice $\cdot$ Guidelines

Offprint requests to: T. Tsuyuguchi

Received: October 1, 2007 / Accepted: October 22, 2007

\section{Introduction}

More than 20 years have passed since stents began to be used for treating unresectable bile duct stricture in patients with obstructive jaundice. Previously, percutaneous transhepatic cholangial drainage (PTCD); also known as percutaneous transhepatic biliary drainage (PTBD) was employed for patients with this disease, and the patients were often forced to stay in hospital for a long period of time with an external biliary fistula. The creation of an internal fistula is now widely used because it is as useful as surgical bypass in improving not only quality of life (QOL) but also survival rates. Today, noninvasive endoscopic stent placement is being used for most patients with this disease as an alternative procedure to the percutaneous approach. Plastic stents (PS), which have been used until now, are economical, but their shortcoming is that they give rise to obstruction at an earlier stage, so several improvements have been made. On the other hand, metal stents (MS), in which the insertion of the stents is enabled with a slender delivery system and the stents expand to a large diameter by themselves, have conferred noticeably extended patency compared with PS. However, their shortcomings are that they are more expensive than PS and replacing them is difficult once they have been placed.

Here we pose clinical questions (CQs) regarding stenting for obstructive jaundice in patients with unresectable biliary carcinoma, with responses in the form of recommendations (grades of the recommendations are defined in Table $1^{1}$ ). Also, levels of evidence are given (in parentheses) for findings in reference citations (see definitions of levels in Table $2^{1}$ ). 
CQ 1 Is biliary drainage recommended for patients with unresectable disease?

\section{Biliary drainage should be performed (recommendation B).}

There are many studies reporting the approach route of drainage for unresectable malignant distal biliary obstruction, methods of stenting, and the quality of stent materials. In view of this situation, it is thought that the relief of jaundice should be conducted as a matter of

Table 1. Strength of recommendations ${ }^{1}$

A, Strongly recommend performing the clinical action

$\mathrm{B}$, Recommend performing the clinical action

$\mathrm{C} 1$, The clinical action may be considered although there is a lack of high-level scientific evidence for its use. May be useful

$\mathrm{C} 2$, Clinical action not definitively recommended because of insufficient scientific evidence. Evidence insufficient to support or deny usefulness

$\mathrm{D}$, Recommend not performing the clinical action course. Also, the creation of an internal fistula, where possible, is recommended.

For the drainage route, there are reports of randomized controlled trials (RCTs) ${ }^{2,3}$ (level II) comparing endoscopic drainage, PTBD, and surgical drainage. The success rate for the creation of an internal fistula is reported to be $95 \%-100 \%{ }^{4,5}$ (levels II, IV). According to these reports, endoscopic drainage is preferable to the other two methods. A metaanalysis showed that endoscopic drainage was associated with a lower risk of complications, but a higher risk of recurrent biliary obstruction than surgical drainage ${ }^{4}$ (level II). The percutaneous procedure is performed in patients in whom the endoscopic procedure has been unsuccessful.

Concerning the types of stent available, there are several RCTs suggesting the superiority of metal stents over plastic stents with respect to stent patency ${ }^{4-12}$ (level II).

For hepatic hilar bile duct stricture, placement of multiple stents has been reported to confer better drainage effects than those brought about by single-stent placement $^{13}$ (level IV), although there are also prospective trials demonstrating that single stents are as effective as

Table 2. Levels of evidence ${ }^{1}$

\begin{tabular}{ll}
\hline Level I & Systematic review/meta-analysis \\
Level II & One or more randomized clinical trials \\
Level III & Nonrandomized controlled trials \\
Level IV & Analytic epidemiology (cohort studies and case-control studies) \\
Level V & Descriptive study (case reports and case-series studies) \\
Level VI & $\begin{array}{l}\text { Opinions of expert panels and individual experts not based on } \\
\text { patient's data }\end{array}$ \\
\hline
\end{tabular}

Table 3. Prospective and randomized controlled trials for plastic versus metal stents in the palliative treatment of distal malignant biliary obstruction ${ }^{6-11,20}$

\begin{tabular}{|c|c|c|c|c|c|c|c|c|}
\hline Reference & $\begin{array}{l}\text { Stent } \\
\text { group }\end{array}$ & $\begin{array}{c}\text { No. of } \\
\text { patients }\end{array}$ & $\begin{array}{c}\text { Stent } \\
\text { occlusion }\end{array}$ & $P$ & $\begin{array}{l}\text { Stent patency } \\
\text { (months) }\end{array}$ & $P$ & $\begin{array}{l}\text { Median survival } \\
\text { (months) }\end{array}$ & $P$ \\
\hline \multirow{2}{*}{$\begin{array}{l}\text { Davids et al., } \\
1992\end{array}$} & MS & 49 & 16 & \multirow[t]{2}{*}{ NR } & 9.1 & \multirow[t]{2}{*}{0.006} & 5.8 & \multirow[t]{2}{*}{0.45} \\
\hline & PS & 56 & 30 & & 4.2 & & 4.9 & \\
\hline \multirow{2}{*}{$\underset{1993}{\text { Knyrim et al., }}$} & MS & 31 & 6 & \multirow[t]{2}{*}{ NR } & 6.2 & \multirow[t]{2}{*}{ NR } & NR & \multirow[t]{2}{*}{ NR } \\
\hline & PS & 31 & 10 & & 4.6 & & NR & \\
\hline \multirow[t]{3}{*}{ Prat et al., ${ }^{8} 1998$} & MS & 34 & NR & \multirow[t]{3}{*}{ NR } & 4.8 & \multirow[t]{3}{*}{$<0.05^{\mathrm{e}}$} & 4.5 & \multirow[t]{3}{*}{ NS } \\
\hline & $\mathrm{PS}^{\mathrm{a}}$ & 34 & NR & & 3.2 & & 5.6 & \\
\hline & $\mathrm{PS}^{\mathrm{b}}$ & 33 & NR & & 3.2 & & 4.8 & \\
\hline \multirow{2}{*}{$\begin{array}{l}\text { Kaassis et al., } \\
2003\end{array}$} & MS & 59 & 11 & \multirow[t]{2}{*}{$<0.007$} & NR & 0.007 & 5.1 & \multirow[t]{2}{*}{ NS } \\
\hline & PS & 59 & 22 & & 5.5 & & 3.3 & \\
\hline \multirow{2}{*}{$\begin{array}{l}\text { Katsinelos et al., }{ }_{2006}^{10} \\
\end{array}$} & MS & 23 & 23 & \multirow[t]{2}{*}{$\mathrm{NS}$} & 8.5 & 0.002 & 9.1 & \multirow[t]{2}{*}{ NS } \\
\hline & $\mathrm{PS}^{\mathrm{c}}$ & 24 & 24 & & 4.1 & & 6.9 & \\
\hline Soderlund et al., & $\mathrm{MS}^{\mathrm{d}}$ & 49 & 9 & 0.009 & 3.6 & 0.002 & 5.3 & 0.27 \\
\hline 2006 & PS & 51 & 22 & & 1.8 & & 3.9 & 76 \\
\hline
\end{tabular}

MS, metal stent; PS, plastic stent; NR, not reported; NS, not significant

${ }^{a}$ Stent exchanged every 3 months with or without evidence of stent dysfunction

${ }^{\mathrm{b}}$ Stent exchanged on evidence of stent dysfunction

${ }^{\mathrm{c}}$ Tannenbaum stent

${ }^{\mathrm{d}}$ Covered MS

${ }^{\mathrm{e}}$ MS versus $\mathrm{PS}^{\mathrm{a}}$ and $\mathrm{PS}^{\mathrm{b}}$ 


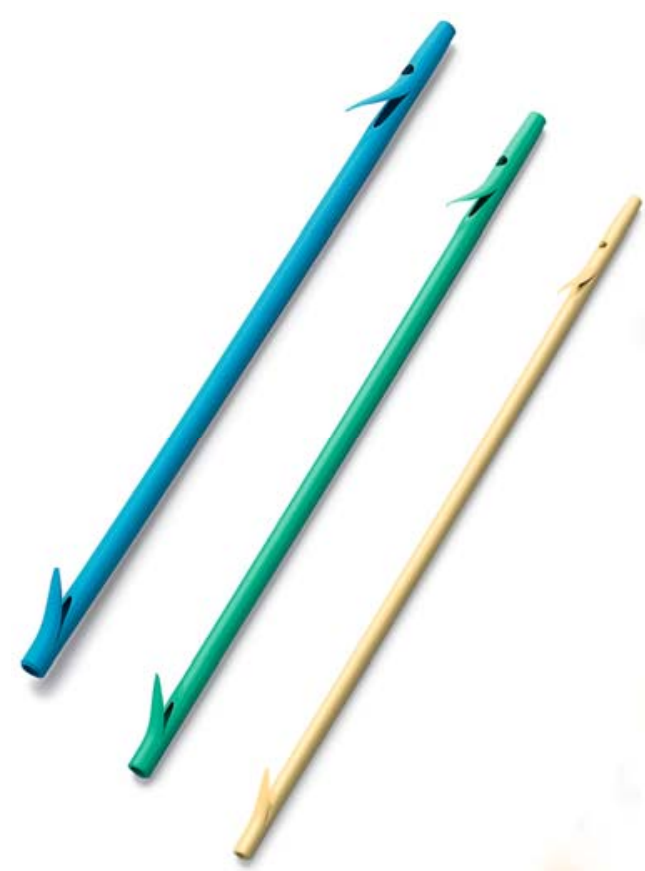

Fig. 1. Plastic stents. From left, plastic stents with outer diameters of $10,8.5$, and $7 \mathrm{Fr}$, are shown

multiple stents ${ }^{14,15}$ (levels II, III). However, there are several questions as to hepatic hilar bile duct stricture, such as the presence of segments for which drainage is unable to be achieved and the clogging of stents, so stent placement in these patients is still controversial.

\section{CQ 2 Which type of biliary stent is appropriate for} unresectable cases?

\section{A metal stent is preferable in view of stent patency (recommendation C1).}

Plastic stents with an outer diameter of $8-10 \mathrm{Fr}$ are now in use (Fig. 1). These are easily clogged, so stents with a larger diameter have occasionally been employed in the past. However, due to the pain and technical difficulties accompanying the insertion of these stents, they have fallen into disuse. Improvements have been made in the quality of materials and the shape of stents, but no difference in patency rates has been observed ${ }^{16-19}$ (level II).

There are RCTs comparing plastic stents with metal stents in the palliative treatment of distal malignant biliary obstruction ${ }^{4-11}$ (level II). As for the median patency of stents, metal stents (3.6-9.1 months) are significantly superior to plastic stents (1.8-5.5 months), but no difference was found in median survival (Table 3$){ }^{20}$ Although metal stents are expensive, their overall cost,

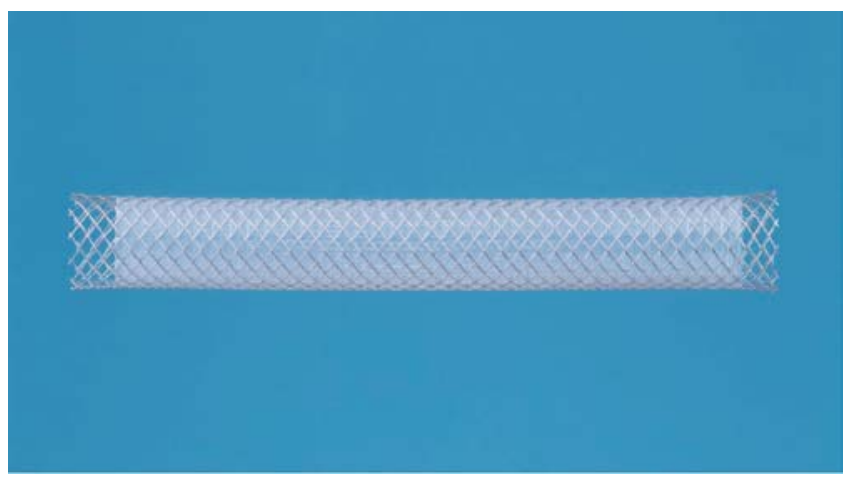

Fig. 2. Covered metal stent (Wallstent; Boston Scientific, Natick, MA, USA). This metal stent is partially covered

including hospitalization expenses, is thought to be lower compared with that of plastic stents because of the reduced frequency of re-intervention. ${ }^{6,7}$ According to recent reports, the cost of plastic stents is low for the reasons that, in patients for whom prognosis is poor, long-term survival is not expected (patients with liver metastasis) and re-intervention is also unnecessary. ${ }^{8-10}$ In patients for whom long-term survival exceeding 6 months is expected, metal stents may be used from the initial intervention, while in patients for whom survival exceeding 6 months is not expected, similar results are achieved by using plastic stents (level IV).

In metal stents, which are made of mesh materials, obstruction due to the ingrowth of tumors has often occurred. To cope with this problem, polyurethanecovered metal stents have become available in clinical settings (Fig. 2) ${ }^{21}$ (level IV), and their superior patency has been demonstrated by an $\mathrm{RCT}^{22}$ (level II). Recent case series studies, however, reported that no significant difference in patency rate was found between covered and uncovered metal stents, because covered metal stents have several drawbacks, such as stent-migration and the occurrence of acute cholecystitis ${ }^{23-25}$ (level IV). Furthermore patients with pancreatic cancer have been included in the results of studies of stent treatment for malignant distal biliary stricture. Accumulation of evidence is awaited.

There is much controversy as to the importance of establishing drainage of both liver lobes in malignant hilar biliary obstruction. Drainage with a unilateral uncovered metal stent is reported to be effective for hilar biliary obstruction ${ }^{15,26,27}$ (level III, IV); however, there are no RCTs regarding unilateral or bilateral metal stent drainage. Concerning plastic stents, an RCT failed to find any difference in drainage effects between single stents and multiple stents ${ }^{15}$ (level II). Although an $\mathrm{RCT}^{12}$ (level II) regarding plastic stents and metal stents showed that both success and patency rates were better for metal stents than for plastic stents, the RCT 
included only 20 patients with hilar biliary obstruction. Hence, it is still controversial which type of stents should be used in patients with hilar biliary obstruction.

Acknowledgment. We would like to express our deep gratitude to the members of the the Japanese Association of Biliary Surgery, the Japanese Society of HepatoBiliary-Pancreatic Surgery, and the Japan Society of Clinical Oncology, who provided us with great support and guidance in the preparation of the Guidelines. This process was conducted as part of the Integrated Research Project for Assessing Medical Technology 2005 and 2006 sponsored by the Japanese Ministry of Health, Labour, and Welfare.

We truly appreciate the following active working members who developed the draft of the evidencebased clinical practice Guidelines for the treatment of biliary tract cancer (Japanese version, 2007): Masahiro Kai (Miyazaki), Yasutoshi Kimura (Sapporo), Shigeaki Sawada (Toyama), Hiroaki Shimizu (Chiba), Hisatoshi Nakagawara (Kanazawa), Kohei Nakachi (Kashiwa), and Hiroyuki Yoshitome (Chiba). We also appreciate very much the following members who reviewed and approved the final Japanese version of the guidelines: Hiromitsu Saisyo (Ichikawa), Munemasa Ryu (Chiba), Satoru Shikata (Kyoto), and Yuji Nimura (Nagoya).

\section{References}

1. Takada T, Miyazaki M, Miyakawa S, Tsukada K, Nagino M, Kondo $\mathrm{S}$, et al. Purpose, use, and preparation of clinical practice guidelines for the management of biliary tract and ampullary carcinomas. J Hepatobiliary Pancreat Surg 2008;15:2-6.

2. Speer AG, Cotton PB, Russell RC, Mason RR, Hatfield AR, Leung JW, et al. Randomised trial of endoscopic versus percutaneous stent insertion in malignant obstructive jaundice. Lancet 1987;2:57-62.

3. Smith AC, Dowsett JF, Russell RC, Hatfield AR, Cotton PB. Randomised trial of endoscopic stenting versus surgical bypass in malignant low bile duct obstruction. Lancet 1994;344:1655-60.

4. Moss AC, Morris E, Leyden J, MacMathuna P. Malignant distal biliary obstruction: a systematic review and meta-analysis of endoscopic and surgical bypass results. Cancer Treat Rev 2007; 33:213-21.

5. Madoff DC, Wallace MJ. Palliative treatment of unresectable bile duct cancer: which stent? Which approach? Surg Oncol Clin N Am 2002;11:923-39.

6. Davids PH, Groen AK, Rauws EA, Tytgat GN, Huibregtse K. Randomized trial of self-expandanding metal stents versus polyethylene stents for distal malignant biliary obstruction. Lancet 1992;340:1486-92.

7. Knyrim K, Wagner HJ, Pausch J, Vakil N. A prospective randomized, controlled trial of metal stents for malignant obstruction of the common bile duct. Endoscopy 1993;25:207-12.

8. Prat F, Chapat O, Ducot B, Ponchon T, Pelletier G, Fritsch J, et al. A randomized trial of endoscopic drainage methods for inoperable malignant strictures of the common bile duct. Gastrointest Endosc 1998;47:1-7.
9. Kaassis M, Boyer J, Dumas R, Ponchon T, Coumaros D, Delcenserie $\mathrm{R}$, et al. Plastic or metal stents for malignant stricture of the common bile duct? Results of a randomized prospective study. Gastrointest Endosc 2003;57:178-82.

10. Katsinelos P, Paikos D, Kountouras J, Chatzimavroudis G, Paroutoglou G, Moschos I, et al. Tannenbaum and metal stents in the palliative treatment of malignant distal bile duct obstruction: a comparative study of patency and cost effectiveness. Surg Endosc 2006;20:1587-93.

11. Soderlund C, Linder S. Covered metal versus plastic stents for malignant common bile duct stenosis: a prospective, randomized, controlled trial. Gastrointest Endosc 2006;63:986-95.

12. Wagner HJ, Knyrim K, Vakil N, Klose KJ. Plastic endoprostheses versus metal stents in the palliative treatment of malignant hilar biliary obstruction. A prospective and randomized trial. Endoscopy 1993;25:213-6.

13. Chang WH, Kortan P, Haber GB. Outcome in patients with bifurcation tumors who undergo unilateral versus bilateral hepatic duct drainage. Gastrointest Endosc 1998;47:354-62.

14. De Palma GD, Galloro G, Siciliano S, Iovino P, Catanzano C. Unilateral versus bilateral endoscopic hepatic duct drainage in patients with malignant hilar biliary obstruction: results of a prospective, randomized, and controlled study. Gastrointest Endosc 2001;53:547-53.

15. De Palma GD, Pezzullo A, Rega M, Persico M, Patrone F, Mastantuono L, et al. Unilateral placement of metallic stents for malignant hilar obstruction: a prospective study. Gastrointest Endosc 2003;58:50-3.

16. Schilling D, Rink G, Arnold JC, Benz C, Adamek HE, Jakobs R, et al. Prospective randomized single-center trial comparing three different 10-F plastic stents in malignant mid and distal bile duct strictures. Gastrointest Endosc 2003;58:54-8.

17. Terruzzi V, Comin U, De Grazia F, Toti GL, Zambelli A, Beretta $\mathrm{S}$, et al. Prospective randomized trial comparing Tannenbaum Teflon and standard polyethylene stents in distal malignant biliary stenosis. Gastrointest Endosc 2000;51:23-7.

18. Barkun AN. A prospective randomised multicentre trial comparing $10 \mathrm{~F}$ Teflon Tannenbaum stents with $10 \mathrm{~F}$ polyethylene CottonLeung stents in patients with malignant common duct strictures. Gastrointest Endosc 2001;53:399-401.

19. van Berkel A-M, Huibregtse IL, Bergman JJGHM, Rauws EAJ, Bruno MJ, Huibregtse K. A prospective randomized trial of Tannenbaum-type Teflon-coated stents versus polyethylene stents for distal malignant biliary obstruction. Eur J Gastroenterol Hepatol. 2004;16:213-7.

20. Levy MJ, Baron TH, Gostout CJ, Petersen BT, Farnell MB. Palliation of malignant extrahepatic biliary obstruction with plastic versus expandable metal stents: an evidence-based approach. Clin Gastroenterol Hepatol 2004;2:273-85.

21. Hausegger KA, Thurnher S, Bodendorfer G, Zollikofer CL, Uggowitzer M, Kugler C, et al. Treatment of malignant biliary obstruction with polyurethane-covered Wallstents. AJR Am J Roentgenol 1998;170:403-8.

22. Isayama H, Komatsu Y, Tsujino T, Sasahira N, Hirano K, Toda N, et al. A prospective randomised study of "covered" versus "uncovered" diamond stents for the management of distal malignant biliary obstruction. Gut 2004;53:729-34.

23. Park DH, Kim M-H, Choi JS, Lee SS, Seo DW, Kim JH, et al. Covered versus uncovered Wallstent for malignant extrahepatic biliary obstruction: a cohort comparative analysis. Clin Gastroenterol Hepatol 2006;4:790-6.

24. Yoon WJ, Lee JK, Lee KH, Lee WJ, Ryu JK, Kim Y-T, et al. A comparison of covered and uncovered Wallstents for the management of distal malignant biliary obstruction. Gastrointest Endosc 2006;63:996-1000.

25. Fumex F, Coumaros D, Napoleon B, Barthet M, Laugier R, Yzet $\mathrm{T}$, et al. Similar performance but higher cholecystitis rate with covered biliary stents: results from a prospective multicenter evaluation. Endoscopy 2006;38:787-92. 
26. Cheng JLS, Bruno MJ, Bergman JJ, Rauws EA, Tytgat GN, Huibregtse K. Endoscopic palliation of patients with biliary obstruction caused by nonresectable hilar cholangiocarcinoma: efficacy of self-expandable metallic Wallstents. Gastrointest Endosc 2002;56:33-9.
27. Freeman ML, Overby C. Selective MRCP and CT-targeted drainage of malignant hilar biliary obstruction with self-expanding metallic stents. Gastrointest Endosc 2003;58:41-9. 